\title{
EUROPA EN LA HISTORIA UNIVERSAL: UNA LECTURA DECOLONIAL DESDE LA FILOSOFÍA DE LA LIBERACIÓN
}

\section{ISABEL GUERRA NARBONA ${ }^{1}$}

RESUMEN: Este trabajo es una crítica a la subjetividad moderna europea, que, a partir del siglo XVIII, ha impuesto al mundo una pretendida superioridad. Desde el diálogo con la Filosofía de la Liberación, podremos deconstruir ese mito de la Modernidad, y situar correctamente a Europa en la Historia Universal para mostrar su verdadero rostro. Como europeos necesitamos partir de un nuevo discurso, reconociendo públicamente el lugar que hemos ocupado en la Historia Universal. Solo a través de este reconocimiento de lo que somos podremos abrirnos a una nueva subjetividad más allá de la Voluntad de Poder, que ha sembrado tanto sufrimiento en la periferia.

PALABRAS CLAVES: Europa, Historia Universal, Voluntad de Poder, Vida y liberación.

ABSTRACT: This work is a critique of modern European subjectivity, which, since the 18th century, has imposed a pretended superiority on the world. From the dialogue with the Philosophy of Liberation, we can deconstruct that myth of Modernity, and place Europe in the Universal History to show its true face. As Europeans we need to start from a new discourse, publicly acknowledging the place we have occupied in the Universal History. Only through this recognition of who we are can we open ourselves to a new subjectivity beyond the Will to Power, which has sown so much suffering on the periphery.

KEYWORDS: Europe, Universal History, Will to Power, Life and liberation.

Este artículo, que lleva por nombre "Europa en la Historia Universal", fue escrito inspirado en el capítulo"Iberoamérica en la Historia Universal", perteneciente a la obra América Latina: dependencia y liberación, que había publicado el filósofo Enrique Dussel, en 1973. A pesar de que esta obra aún no contiene las categorías y conceptos propios y definitivos de la Filosofía de la Liberación, sí ha desarrollado una crítica muy enriquecedora preocupada por encontrarle a Iberoamérica su lugar en la Historia Universal. No estará de más expresar que, tal vez, este sea el primer paso - y podría considerarse el más importante - para cualquier pueblo oprimido que adquiera conciencia real de su ser verdadero, lo que, en el futuro, le ayudará a liberarse del yugo de la dominación. De hecho, el re-conocimiento que adquiere un pueblo en relación al lugar que ocupa en la Historia Universal es la antesala de toda crítica política, cultural, económica o religiosa dirigida en contra de cualquier sistema político totalitario que

\footnotetext{
${ }^{1}$ Professora da Universidad Nacional Autónoma de México (UNAM). Doutora em Filosofia pela Universidad de Sevilla (US). E-mail: guerranarbona@ hotmail.com.
} 
le mantenga en una situación de enajenación, y, por tanto, propiciará la posibilidad para una futura liberación. Pero, ¿qué ocurre cuando la Historia Universal que se ha impuesto es falsa o está manipulada? Esta cuestión me hizo reflexionar sobre el lugar real que ocupa Europa en dicha Historia. Si, sencillamente, un pueblo descubre su lugar en la Historia, y esto le permite defender su particularidad, su identidad frente a sus opresores; Europa sólo podría conocer su particularidad cultural, esto es, su "ser verdadero", si primero deconstruye públicamente esa fabulosa Historia que impuso violentamente al mundo como verdadera, y que realmente vino a ser el mito romántico de la dominación. Pero ese descubrimiento viene alumbrado por la propia historia de la opresión del Otro. Es el no ser del Otro, desde la exterioridad, el que puede mostrar a Europa su verdadero rostro.

En cualquier caso, los europeos también debemos conocer y aceptar nuestro verdadero ser. Debemos enfrentarnos a él históricamente para liberarnos del fabuloso mito que construimos en el pasado, y que ha causado y está causando tanto sufrimiento a la Humanidad. Si nosotros, como europeos, somos conscientes plenamente de nuestra verdadera identidad como totalidad dominadora, si la asumimos responsablemente, tendremos la posibilidad de transformar nuestra subjetividad en una nueva que afirme la Vida y al Otro. Hecho que supondría, por completo, el destronamiento de la sociedad capitalista, de la opresora Modernidad. En cualquier caso, este trabajo reconstruye la historia de cómo se fue configurando nuestra subjetividad moderna, desde un diálogo con la Filosofía de la Liberación y su exterioridad.

\section{1.- Repensar Europa en la Historia Universal}

La historia de Occidente y de la "razón" que nos construye cada día nuestra era moderna y la alienta dulcemente con su aparente entusiasmo de aire triunfador, es, en realidad, la historia de la destrucción de la Vida en nuestro planeta, y, por eso, nuestro progreso no es más que un mito, cuyo eco se ha quedado divagando entre la esperanza de un mundo digno de dioses y la desesperación que causa el saber que convivimos con la aniquilación de lo sagrado, y que, tal vez, seamos nosotros mismos, los occidentales, con nuestro afán de superarnos los unos a los otros, los que lo hayamos provocado. Porque esta destrucción de la vida humana, animal y vegetal y la contaminación de la atmósfera son la manifestación física de un proceso histórico y cultural, pero también ontológico, que yo misma, en estos últimos años, he llamado la desmitificación de la Vida, y que tiene que ver, precisamente, con el hecho de que la subjetividad europea, a partir del siglo XVII, haya dejado de concebir al cosmos y a la Naturaleza como entidades sagradas, y las empezara a percibir como si fueran máquinas, 
simples relojes a los que fácilmente se les puede cambiar la hora, si con ello se logra llegar puntual a la era civilizatoria y dominadora de la Historia.

Por ello, el punto de partida de este trabajo es una crítica a la subjetividad europea. A partir del siglo XVIII con la Ilustración y el Romanticismo, muchos eruditos e intelectuales de renombre se encargaron de glorificar la imagen de Europa - como si ésta fuera todo un prodigio desde tiempos inmemoriales - con el fin de servir de modelo histórico y civilizatorio a las demás culturas que configuran el puzzle desquiciado del mundo. Tal osadía nos condujo a un grave y lamentable error. Primero, porque nos fuimos desarrollando cultural y históricamente sobre el sueño de un mito, sobre la historia fabulosa de una mentira; y segundo, porque en nombre de esa mentira, que nos creó como un hito universal, hemos cometido atrocidades que, todavía hoy, no hemos sabido reconocer con suma humildad y humanidad, esto es, con verdadera conciencia ética planetaria. El resultado, pues, se refleja en la sobre-explotación del hombre y de la Naturaleza, y en su consecuente aniquilación.

Pero por mucho que nos avergüence la verdad, debemos reconocer que la Europa que en este momento somos hunde sus raíces originarias en un pasado caracterizado por la decadencia cultural e intelectual, y, de alguna manera, este hecho había dado lugar a un profundo complejo de inferioridad, frente a otras culturas, como la árabe o la china, que por aquel tiempo sí fueron grandes hitos históricos en la franja comprendida por el horizonte indoafro-asiático. Saber hasta qué punto nuestra subjetividad patológica es la responsable de tanto sufrimiento y dolor en el mundo es reconocer el lugar propio que esta Europa ha ocupado en la Historia. Y, de algún modo, situarnos como europeos "con precisión intelectual y ética en la Historia Universal” - como comentó el mismo Enrique Dussel cuando se refería a Iberoamérica - nos ayudará a ser autoconscientes de nuestra propia identidad para sanar esta vieja enfermedad que aún, quizá hoy, no ha presentado sus peores síntomas a la humanidad y a la Tierra. Lo que significa no sólo tener en cuenta nuestras hazañas "heroicas", sino también tener presente al Otro, a la Otra cultura, como parte esencial de la historia pasada y contemporánea, que, por supuesto, también es protagonista de primera mano en el fenómeno de la Modernidad ${ }^{2}$. En todo caso, para conocer nuestra Europa real, y tener una idea clara y verosímil de ésta, también hace falta una comprensión del lugar, y el papel, que ocuparon las demás culturas en la Historia Universal. En este sentido, la Filosofía de la Liberación nos puede aportar claves significativas

\footnotetext{
${ }^{2}$ Para Dussel, el concepto de Modernidad tiene un sentido diferente con respecto a como lo ha ido entendiendo Europa. Como expresa el filósofo mexicano: "La Modernidad (el capitalismo, el colonialismo, el primer sistemamundo) no es coetánea de la hegemonía de Europa, jugando la función de "centro" del sistema con respecto a las restantes culturas. 'Centralidad" del sistema-mundo y Modernidad no son fenómenos sincrónicos. La Europa moderna llega a ser 'centro' después de ser 'moderna'" (Dussel, 2006: 46).
} 
de nuestra propia esencia: la Voluntad de Poder. Creo, entonces, que ha llegado el momento de situarnos en otro horizonte reflexivo del que hasta ahora estábamos acostumbrados los europeos, y cultivar otra actitud frente a la Vida, por supuesto, desde otra subjetividad: La Voluntad de Vida, que tiene por fundamento el reconocimiento de la dignidad del Otro. Sería por tanto enriquecedor tomar como ejemplo la subjetividad humilde y reflexiva de las otras filosofías, que se han ido desarrollando dolorosamente en la sombra de Europa, en su exterioridad, en gran parte, por la en-carnación de un mito que empezó a construirse violentamente como una verdad irrevocable, cuyo objetivo primordial no fue otro que devorar las otredades del Otro. En este sentido, en nuestro trabajo hemos tomado muy en serio la Filosofía de la Liberación ${ }^{3}$. Esta genuina filosofía, nacida a finales de los años sesenta, ha hecho una contribución novedosa para la filosofía universal gracias a que su enfoque se ha ido configurando a través del diálogo y la reflexión con numerosos filósofos y corriente de pensamiento europeo y norteamericano, así como también de otros movimientos filosóficos surgidos en la periferia, que han tratado directa o indirectamente el tema del poder, como por ejemplo Nicolás Maquiavelo, Friedrich Nietzsche, Karl Marx, Emmanuel Lévinas, Paul Ricoeur, Max Weber, Ernesto Laclau, Paolo Freire, Karl-Otto Apel, Franz Hinkelammert, Raúl Fornet-Betancourt o John Holloway.

En cualquier caso, como veníamos diciendo anteriormente, Europa había sido "mitificada", al haberse idealizado a la manera de Hegel, por ejemplo. A partir del siglo XVIII, se había impuesto un único modelo de pensamiento y de ser humano que las culturas marginadas y excluidas debían asimilar y adoptar como propios, con lo cual se terminó por infravalorar y despreciar sus particularidades culturales y ontológicas. Para Enrique Dussel,

\footnotetext{
${ }^{3}$ En la autobiografía que Dussel escribió acerca de las etapas e ideas más importantes que contribuyeron a la creación de la Filosofía de la Liberación, podemos leer lo siguiente: "Por ello, se buscarán algunos elementos para la descripción autobiográfica que puedan dar razón de la elaboración racional (y del texto) del sujeto que se reconstruye en su autobiografía; obra (texto) que denominaremos desde hace años Filosofía de la Liberación tengo conciencia de haberla denominado así, en el claro oscuro de la conciencia y del inconsciente, entre 1969 a 1970, cuestión que otros compañeros componentes originarios del movimiento esclarecerán por su parte" (Dussel, 1998a:13).
} 
como latinoamericano, consciente de su otredad ${ }^{4}$, tuvo gran significación e importancia "desoccidentalizarse", y encontrarle a Iberoamérica ${ }^{5}$ su lugar propio en la Historia Universal":

De allí la crisis de muchos pensadores que sueñan con una Europa perfecta y lejana, y luchan por imitarla en Latinoamérica; al fin solo alcanzan la conmiseración del europeo y la incomprensión del latinoamericano. Muy por el contrario, si descubrimos nuestro camino entenderemos que para ser oídos en Europa o Asia, es necesario que presentemos sin equívocos nuestra personalidad - nuestro temple, nuestra "cara" - latinoamericana. Para ello "Latinoamérica" debe dolernos, debe desesperanzarnos, debe tornase problemática, debe ser el objeto mismo de nuestra reflexión" (Dussel, 1973:21).

De igual manera, Europa debe saber situarse con suma precisión en la Historia Universal, en su caso, para trasformar nuestra subjetividad y liberarnos de un mito destructor de la Vida. También, para nosotros, como cultura eurocéntrica, este ejercicio de autoconciencia conlleva un proceso doloroso que se manifiesta desde una cierta angustia, porque nos pone en continua auto-cuestión, y esto supone que debamos desmitificarnos frente a la humanidad sagrada del Otro. Como europeos deberemos, entonces, afrontar primero nuestra falta de responsabilidad histórica, y cambiar la actitud soberbia frente a las otras culturas, frente a la exterioridad que nos señala. No olvidemos que nuestra falta de amor a la vida ha causado grandes estragos en todo el planeta, desde que España invadiera a Amerindia, e impusiera una opresión injustificada al indio, o ya, incluso, desde mucho antes, cuando no supimos reconocer con dignidad lo pequeños que éramos. Ahora bien, este sometimiento ha obligado a todas las

\footnotetext{
4 "Un día Kant descubrió que, gracias a la lectura de los empirístas ingleses, se 1despertaba del sueño racionalista'.Un día sentí despertarme, en el estudio y la experiencia, del sueño reductivo del siglo XIX. Llamo siglo reductivo (de "reducción", es "reducir" algo a uno de sus componentes negando o dejando de lado otros) a todo aquel intento anti-humanista por el que, paulatinamente, se fue negando la trascendencia en favor de una concepción materialista, positivista, recta y europeista" (Dussel, 1998a:31). También, en este sentido, Europa tiene que despertar de su enigmático pero dañino mito.

${ }^{5}$ Dussel se encuentra muy cercano al enfoque que estaba desarrollando en los años cincuenta el filósofo mexicano Leopoldo Zea desde su obra América en la historia. Al respecto, expresa: "En efecto, como profesor de filosofía e historia de la cultura en Resistencia (Chaco, Argentina), escribí un curso completo, todavía inédito, sobre Hipótesis para el estudio de Latinoamérica en la Historia Universal, donde desarrollé íntegramente una visión hermenéutica de América desde el Asia, en nuestra primera historia (protohistoria) y ahora sí descubriendo su lugar en la Historia Universal. Y desde Europa, desde las invasiones indoeuropeas y semitas hasta el origen de la Modernidad: 1492" (Dussel, 1998a:19).

${ }^{6} \mathrm{Y}$ este hecho es esencial para, no sólo Latinoamérica, sino también para cualquier otra cultura que se encuentre atrapada en un ser que no le es propio. Al respecto, expresa el filósofo de la liberación: "Debemos decir, que es necesario descubrir el lugar que le toca a América latina del huso que se utiliza esquemáticamente en la representación de la evolución de la Humanidad" (Dussel, 1973: 65). En este sentido, Dussel rastreó el origen de Latinoamérica para situarla después en un momento de la Historia o civilización universal. Así, expresa: "desde el vértice inferior - origen de la especie humana en un mono o polifilismo - por un proceso de expansión y diferenciación, se constituyeron las diversas razas, culturas y pueblos. En un segundo momento - el presente -, por la comprensión y convergencia, se va confluyendo hacia una civilización universal. América latina se encamina igualmente hacia esa unidad futura. Explicar las conexiones con su pasado remoto - tanto en la vertiente india como hispánica -, y su futuro próximo, es desvelar inteligiblemente la historia de ese grupo cultural, y no ya con la simpleza del anecdotario o la incongruencia de momentos estancos y sin sentido de continuidad o la invención del político sin escrúpulos (Dussel, 1973: 65).
} 
culturas, sin apenas excepción, a tener que abandonar sus propias identidades, su ser único y valioso, y para sobrevivir no tuvieron más remedio que imitar ${ }^{7}$ a su dominadora en todos sus ámbitos prácticos y de pensamiento. Pero el hecho insólito de ser una triste copia de la "grande Europa" ha tenido efectos muy negativos y destructivos, que se hacen visibles en el desquiciamiento cultural que han sufrido muchas comunidades, que tuvieron que renunciar a sus propios modos de vida, sus costumbres y tradiciones milenarias, para adoptar una nueva visión de la Vida y del universo - de lo sagrado - incomprensible, para todas ellas, porque se sustentaba en la ceguera y en la corrupción que nacen de una avaricia sin límites. Así que el daño que causamos hace siglos aún sigue creciendo y tomando nuevas y originales formas contradictorias, a veces, difíciles de percibir por una mentalidad añeja y obsoleta que sólo cree en sí misma, en su mito delirante. Por ese motivo:

La historia de América ibérica se muestra heterogénea e invertebrada en el sentido de que por un proceso de sucesivas influencias extranjeras se va constituyendo - por reacción - una civilización y cultura latinoamericana. Dicha cultura, en su ausencia, no es el fruto de una evolución homogénea y propia, sino que se forma y conforma según las inmediaciones que vienen desde afuera, y que cruzando el Atlántico adquieren caracteres míticos - el laicismo de un Littré, por ejemplo, o el positivismo religioso de un Comte, nunca llegaron a ser practicados en Francia con la pureza y pasión que fueron producidas en Latinoamérica Pareciera que una ideología en Europa guarda una cierta proporción y equilibrio con otras, en un mundo complejo y fecundo - porque de la vejez de Europa solo hablan los que no la conocen -. En América, dichas ideologías - como un electrón desorbitado - producen efectos negativos, ideologías utópicas, y, al fin nocivas. (Dussel, 1973: 64)

A pesar de ser ya viejos europeos, aún no somos lo suficientemente conscientes de lo que signifique Europa más allá de nuestras voraces fronteras. Hablamos una lengua colosal con un rico y amplio léxico, capaz de expresar con profundidad interpretativa y gran detalle gramatical la realidad, sin embargo, no logramos entender ni una sola "palabra" pronunciada desde la sensibilidad del Otro, cuando nos interpela acerca de nuestra particular forma de ser en el mundo. Así, la riqueza y la "libertad" en Europa se traducen en el rostro inverosímil de la miseria y la esclavitud en la periferia; y nuestra melodiosa y armónica palabra "fraternité", que

\footnotetext{
${ }^{7}$ En relación a toda esta cuestión, Enrique Dussel tiene muy claro que el ser latinoamericano puede ser comprendido desde el fenómeno de traslación. De esta manera: "llamamos traslación a ese acto habitual en la historia americana por el cual un contenido intencional europeo, sacado de su contexto y por ello mismo de su equilibrio, irrumpe en el "mundo" latinoamericano naciendo en un momento imprevisto y produciendo efectos diversos de los que produjo en Europa. El Atlántico pareciera operar como un prisma "mitificante" a tal grado que, lo que es real y homogéneamente emergido en una evolución europea irrumpe en Latinoamérica con caracteres de "mito", y siempre heterogéneamente - es decir, no producido por un crecimiento armónico y creativo, "desde adentro"(Dussel, 1973: 45). Habrá entonces que reflexionar seriamente este fenómeno, junto a América latina y el resto del mundo, para comprender también no sólo sus desastrosas consecuencias históricas, sino para encontrar soluciones viables que puedan abrirnos hacia una nueva concepción del respeto y la solidaridad intercultural; hacia una nueva forma de comprender el progreso humano y su vitalidad.
} 
tanta emoción había provocado a partir de la Revolución francesa - cuando se creyó ingenuamente que era posible la bondad humana - inunda completamente el mundo del Otro de un ruido atroz y desorbitado, hasta convertirlo en un lugar inhabitable, precisamente, desértico de paz y de humanidad, vacío de toda esa "pretendida" bondad. Por eso, pese a nuestra gloria erudita, somos, ciertamente, el sufrimiento injustificado del Otro; somos el lamento vivo de la Tierra que agoniza de tristeza y dolor; sus mares de plástico y sus cielos envenenados; su tierra sedienta y sus peces ahogados; somos, por todo ello, la enfermedad de la Vida, y nuestro rostro blanco, idealizado y universalizado, desde hace ya varios siglos, se ha tornado en la imagen pueril de la misma muerte. Es, por ese motivo, que debemos tomar conciencia de nuestro verdadero ser, de lo que significa Europa en la Historia Universal. En este asunto, hay algunos filósofos europeos que ya han mantenido un discurso autocrítico, y es también de ellos de quienes debemos aprender. Pero existen, entre éstos, ciertas diferencias que debemos matizar. Por ejemplo, el discurso crítico que llevó a cabo Bartolomé de Las Casas ${ }^{8}$ en el Consejo de Indias, en el siglo XVI, contra la terrible dominación y crueldad que soportaban los indígenas amerindios tras la conquista y colonización de los europeos nos parece digno de mencionar para tenerlo presente. Por otro lado, se sitúa el discurso de los postmodernos, que habían realizado una crítica demoledora a la Modernidad, y que, aparentemente, podría servirnos para comprender nuestra identidad europea. En dicho sentido, Vattimo ${ }^{9}$, Lyotard ${ }^{10}$ o Derrida habían

\footnotetext{
${ }^{8}$ Para Enrique Dussel, de Las Casas había mostrado una posición política-crítica sorprendente que él mismo incorporaría como presupuesto relevante para una Política de la Liberación. Al respecto, había expresado Enrique Dussel (2007: 17) sobre el filósofo español: "Desarrolla coherentemente una teoría de pretensión universal de verdad, de todo participante serio y honesto (europeo o amerindio, y aún africano o árabe) - contra el relativismo, o el escepticismo a la manera de Richard Rorty - en el diálogo intercultural, lo que no le impide, de todas maneras, articular de modo insigne una posición no sólo de tolerancia (lo que es puramente negativo) sino de plena responsabilidad por el Otro (que es una actitud positiva), desde una pretensión universal de validez que obliga ética y políticamente a tomar 'en serio' los derechos (y por ello también los deberes deducibles de dichos derechos) del Otro, de manera ejemplar hasta el siglo XXI".

${ }^{9}$ Sobre el nihilismo, expresa Vattimo (2007: 23): "El nihilismo está en acción y no se puede hacer un balance de él, pero se puede y se debe tratar de comprender en qué punto está, en qué nos incumbe y a cuáles decisiones y actitudes nos llama. Creo que nuestra posición frente al nihilismo (lo cual significa nuestra colocación en el proceso de nihilismo) se puede definir recurriendo a una expresión que aparece a menudo en los textos de Nietzsche, la expresión 'nihilismo consumado'. El nihilista consumado o cabal es aquel que comprendió que el nihilismo es su (única) chance. Lo que ocurre hoy respecto del nihilismo es lo siguiente: que hoy comenzamos a ser, a poder ser, nihilistas cabales".

${ }^{10}$ Lyotard (2008: 25) expresa el espíritu posmoderno de la siguiente manera: "lo posmoderno sería aquello que alega lo impresentable en lo moderno y en la presentación misma; aquello que se niega a la consolidación de las formas bellas, al consenso de un gusto que permitiría experimentar en común la nostalgia de lo imposible; aquello que indaga por presentaciones nuevas, no para gozar de ellas sino para hacer sentir mejor que hay algo que es impresentable. Un artista, un escritor posmoderno, están en la situación de un filosofo: el texto que escriben, la obra que llevan a cabo, en principio, no están gobernados por reglas ya establecidas, y no pueden ser juzgados por medio de un juicio determinante, por la aplicación a este texto, a esta obra, de categorías conocidas. Estas reglas y estas categorías son lo que la obra o el texto investigan. El artista y el escritor trabajan sin reglas y para establecer las reglas de aquello que habrá sido hecho. De ahí que la obra y el texto tengan las propiedades del acontecimiento; de ahí también que lleguen demasiado tarde para su autor, o, lo que viene a ser lo mismo, que su puesta en obra
} 
desarrollado un complejo discurso en el Norte, y partieron en sus reflexiones y análisis de la Modernidad y del capitalismo tardío. Ellos centraron sus discursos críticos desde el concepto de nihilismo para explicar la experiencia de decadencia del hombre occidental. Ciertamente, se había producido una cierta "desorientación cultural" que había llevado a ciertos pensadores europeos a negar los valores, costumbres y creencias propios de la Modernidad. E, incluso, llegó el momento en el que no se creía en nada; y quizás esta falta de creencia no nos permitía ver, con suma claridad y cierta perspectiva, más allá de nuestro horizonte interpretativo, que, a simple vista, parecía estar problematizado por un inmenso y desquiciante vacío humano cuya procedencia no llegábamos a comprender muy bien. Pero tampoco se creyó en el Otro. Por eso, esta critica postmoderna no puede mostrarnos nuestro rostro europeo verdadero, pues no está conectada directamente con lo que fuimos más allá de nuestras fronteras interpretativas y geográficas. Y, en cierta medida, esto también le había ocurrido a la Escuela de Frankfurt (Marcuse, Adorno y Horkheimer). A pesar de que los presupuestos de esta tradición europea partían de la miseria de la víctima, desde una materialidad negativa donde la Vida era el referente necesario, y de las respectivas críticas a los condicionantes propios de la sociedad industrial liberal y a la razón instrumental, que impedían el desarrollo de una vida digna, no se centraban exclusivamente en una crítica situada desde el sufrimiento de la periferia. Por este motivo, no tiene como referente principal al Otro excluido y dominado. Para la Filosofía de la Liberación, "Horkheimer no se detiene suficientemente en el cómo las víctimas llegan a descubrir éticamente su situación negativa. Se sitúa - como lo hará también Lévinas y tantos otros - tomando la 'perspectiva“ del filósofo-crítico, y no propiamente la de la víctima misma" (Dussel, 1998b: 332).

La cuestión principal es que no supimos vernos más allá de Europa, de la totalidad totalizante en la que estamos inmersos. Pero es, justamente, desde la periferia oprimida, desde donde podemos tomar conciencia y alcanzar la perspectiva suficiente para comprender no sólo la esencia de ese nihilismo y falta de sentido, sino, sobre todo, de nuestra propia subjetividad dominadora. Porque el Otro es, al fin y al cabo, nuestro espejo. En este sentido parece que Sartre supera el enfoque de los postmodernos y de la Escuela de Fránkfort, al haber reconocido públicamente nuestra decadencia humana desde la opresión del Otro. Así, en el prólogo de Los condenados de la tierra, de Franz Fanon, el filósofo francés - con un tono crítico que bien nos puede recordar, en muchos aspectos, a la Filosofía de la Liberación - habla claramente de ese

comience siempre demasiado pronto. Posmoderno será comprender según la paradoja del futuro (post) anterior $(\operatorname{modo}) "$ 
sometimiento europeo que había convertido a los africanos y asiáticos en el pobre y tímido eco de la voz prodigiosa y clarividente de Europa:

La élite europea se dedicó a fabricar una élite indígena; se seleccionaron adolescentes, se les marcó en la frente, con hierro candente, los principios de la cultura occidental, se les introdujeron en la boca mordazas sonoras, grandes palabras pastosas que se adherían a los dientes. Tras una breve estancia en la metrópolis se les regresaba a su país, falsificados. Esas mentiras vivientes no tenían ya nada que decir a sus hermanos; eran un eco; desde París, Londres, Ámsterdam nosotros lanzábamos palabras: “¡Partenón!”, ¡Fraternidad! Y en alguna parte, en África, en Asia; otros labios se abrían: “¡...tenón! ¡....nidad!” Era la edad de Oro. (Sartre, 2019: 7)

Y se dirige, a nosotros, los europeos, con una sinceridad abrumadora a la vez que suspicaz, para que tomemos auto-conciencia de nuestro verdadero ser, esto es, para que despertemos de nuestra hipocresía histórica, la misma que nos había llevado a las contradicciones más escandalosas y ciegas, a los hechos más denigrantes. Lo cierto es que nuestra soberbia nos ha hecho perdernos, y lo que hasta ahora nos parecía muy sensato y comprensible en el pasado, carece, en realidad, de sentido y justicia para el mundo. Debemos, entonces, saber escuchar y reconocer lo que en el fondo ya todos sabemos, aunque sea de manera inconsciente:

\footnotetext{
Escuchen: no perdamos el tiempo en estériles letanías ni en mimetismos nauseabundos. Abandonemos a esa Europa que no deja de hablar del hombre al mismo tiempo que lo asesina por donde quiera que lo encuentra, en todas las esquinas de sus propias calles, en todos los rincones del mundo. Hace siglos.... que en nombre de una pretendida "aventura espiritual" ahoga a casi toda la humanidad". El tono es nuevo. ¿Quién se atreve a usarlo? Un africano, hombre del Tercer Mundo, ex colonizado. Añade: "Europa ha adquirido tal velocidad, local y desordenada... que va... hacia un abismo del que vale más alejarse". En otras palabras: está perdida. Una verdad que a nadie le gusta declarar, pero de la que estamos convencidos todos - ¿no es cierto, queridos europeos? (Sartre, 2019: 9)
}

El europeo no está ciertamente acostumbrado a pedir perdón, ni siquiera a reconocer su falta de responsabilidad histórica ante los otros, sus víctimas. Ha recibido la herencia de ese viejo mito, y se ha sentido digno de reproducirlo y gravarlo con fuego y sangre en la frente de la humanidad; acaso como si el honor de Europa se sustentara en una bella y admirable mentira, que solo nosotros hemos "creído" absolutamente para poder realizar nuestro proyecto imperialista sin remordimientos. En toda esta gran hazaña, la dominación de la Vida la convertimos en una misión política y teológica. Política porque nos permitía tener el derecho de gobernar a los pueblos y naciones; teológica porque dominando la Vida el hombre moderno alcanzaría un estatus superior al mero hombre. Bacon se había convertido en todo un modelo para este nuevo hombre. Sin embargo, el hecho de que existan pensadores autocríticos supone 
ya una ruptura con nuestro ego, cuando en cierto modo se ha dejado de creer en ese mito. Entonces, cabe peguntarnos, ¿la denuncia pública de Sartre ha emergido de una nueva subjetividad más allá de la Europa eurocéntrica? Al menos, se trata del reconocimiento de una verdad histórica y material: Europa ha sembrado injusticia en los campos del mundo, y lo que parecía digno de cosechar era, en realidad, el fruto más amargo de todos.

Ciertamente, debemos reconocer el daño que hemos causado a la Vida en todo el planeta, pero, debemos primero hacer un recorrido por nuestra historia, desmitificarla, aunque tengamos, por ello, que aceptar públicamente, y con cierta vergüenza, nuestro oscuro e insignificante pasado. El simple hecho de reconocer nuestro particular lugar en la Historia Universal será esencial para abrirnos a una nueva subjetividad europea que sepa situarse humildemente en la periferia del mundo, y que nos haga comprender con mayor claridad por qué ese mito del progreso moderno ha traído tanta fatalidad para más del $80 \%$ de la humanidad y por qué nos cuesta tanto asumirlo.

\section{2.- Europa: "aislada y secundaria"}

Existe un gran error histórico que nos viene acompañando hasta el presente: creernos poseedores de la universalidad de la historia. Esta idea forma parte de nuestra subjetividad moderna, pero no es cierto que Europa como tal hubiera sido algo así como la cuna de lo civilizatorio y del futuro progreso de la humanidad desde siempre. Europa ni fue el comienzo ni el fin de la Historia universal, como había advertido el pensador Hegel desde su propio eurocentrismo alemán. Recordemos que Hegel había hecho una interpretación de la Modernidad desde un idealismo exagerado y nada alentador, donde el Espíritu salía fuera de sí para realizar un largo camino hacia la libertad y la autoconciencia. Y, precisamente, el itinerario histórico que recorría ese prodigioso Espíritu (Weltgeist) finalizaba en la Europa occidental. No obstante, frente a esta visión eurocéntrica existe otra versión que debemos manejar seriamente para tener una idea más clara y verosímil de lo que pudo haber sido Europa en la encrucijada histórica de los pueblos. Por eso, me centro en la tesis que defiende el filósofo latinoamericano Enrique Dussel desde la Filosofía de la Liberación, en cierto modo, para entender qué sentido tenía Europa para la Modernidad y quienes fuimos, en realidad, sus legítimos herederos. En cualquier caso, su visión no-eurocéntrica no parte del modelo que Europa, desde la Ilustración francesa e inglesa y los románticos alemanes, viene imponiendo con arrojo violento para convencer al mundo entero de que es la única portadora, desde sus orígenes griegos, de los valores que se fueron universalizando durante la Modernidad. Ciertamente, este modelo 
proyectó a Europa hacia el pasado, y anunció que todo en la Historia Universal había sido preparado e ideado, como en un plan divino, para que la propia Europa fuera el fin y el centro de esa Historia colosal. Para eso, el romanticismo del siglo XVIII había hecho creer la diacronía unilateral Grecia-Roma-Europa (Dussel, 2001: 346). Pero lo cierto es que la Europa nacida del oriente fue algo totalmente diferente de la Europa "definitiva" y moderna. Por eso, es que Dussel (2001: 345) expresa que "a Grecia no hay que confundirla con la futura Europa". Tal vez, Hegel o Kant, y todos los románticos que le siguieron y que en tantas ocasiones soñaron con una Europa inmortal, se hubieran lamentado enormemente al saber que el lugar de esa Europa, que tanto habían elogiado, era ocupado por lo "bárbaro", y que tanto el África como el Asia, que tan mal prensa tuvieron para una ideología que se parecía en muchos aspectos al racismo, eran civilizaciones mucho más adelantadas y avanzadas. En este sentido, la Grecia originaria estaba fuera del alcance de esa Europa que había sido ingenuamente "divinizada", porque, ciertamente, ésta fue considerada por muchos pueblos lo no-civilizado, lo no-político y lo no-humano. Pero además, como expresa el filosofo de la liberación, lo que conocemos como "Occidental" vino a ser el imperio romano que hablaba latín y que se oponía a lo "Oriental”, que era justamente el imperio helenista que hablaba griego. En esta región se situaba Grecia y el Asia, y los reinos helenistas hasta los bordes del Indo; razón por la que la influencia griega no puede considerarse directa en la Europa latina occidental. Así que Europa no mostró relación directa con Grecia, sino más bien con el mundo latino romano occidental cristianizado. Por tanto, como expresa el mismo filosofo mexicano:

La "universalidad musulmana es la que llega del Atlántico al Pacífico. La Europa latina es una cultura periférica y nunca ha sido hasta ese momento "centro" de la historia; ni siquiera con el imperio romano (que por su ubicación extremadamente occidental nunca fue centro ni siquiera de la historia del continente euro-afro-asiático). Si algún imperio fue centro de la historia regional euro-asiática antes del mundo musulmán, sólo podemos remontarnos a los imperios helenistas desde los Seleusidas, Ptolomeicos, el de Antíocos, etc. Pero, de todas maneras, el helenismo no es Europa, y no alcanzó una "universalidad" tan amplia como la musulmana en el siglo XV. (Dussel, 2001: 348)

Europa, la Gran Europa de las eternas luces, no es más que un mito, una historia fabulosa que ha sembrado de cadáveres y de miseria el planeta, y lo ha cubierto de profundos ríos de sangre que no dejan de fluir por los cauces del mundo. A pesar de todo lo que durante siglos se había escrito sobre ésta con tanto decoro y fanatismo - a partir de la Ilustración y del romanticismo del siglo XVIII - lo cierto es que nunca fue como nos contaron esos pretensiosos libros de Historia, cuyo fin no era otro que vanagloriarse de una realidad adornada por un ego venido de una subjetividad que se sentía privilegiada y con el legítimo derecho de dirigir el 
destino de toda la Humanidad hasta la misma incertidumbre, si esto, de alguna manera, le beneficiara o le resultara de su agrado. En cierto modo debemos reconocer que Europa nunca tuvo la sabiduría de los pueblos que fueron sometidos por ella. Y aunque nos cueste asumirlo, porque hemos nacido de su vientre legendario, a la grande Europa nunca le interesó demasiado el conocimiento más que para dominar en el arte de la guerra y de la conquista a los que ella había considerado sus enemigos.

En los primeros siglos de nuestra era, parte del territorio que ahora lo ocupa la Europa moderna estaba atravesando una situación de gran decadencia científica, intelectual, debido, principalmente, a la inestabilidad política que había dividido el Imperio romano en oriental y occidental, tras la muerte de Teodosio, en el año 395. El resultado no podía ser peor: el colapso de un gobierno y la desaparición de la vida urbana habían decantado en un periodo que parecía interminable, de verdadero estancamiento científico. Tiempo después, triunfaría el cristianismo, y la Iglesia se dedicó durante algún tiempo a reclutar reconocidos sabios y pensadores para llevar a cabo ciertas actividades misioneras y doctrinarias. El honor no estaba regido por el avance en conocimientos de los fenómenos naturales, sino más bien se quedó atrapado en los objetivos intransigentes de la Iglesia, y esto se apreció enormemente en un desprecio casi absoluto a la filosofía y ciencia de los antiguos.

En el siglo VI, existieron algunos cristianos que se interesaron por las ciencias, y fue, precisamente, a través de la tradición enciclopédica y de compendios ${ }^{11}$, centrada básicamente en los logros científicos de la Grecia clásica, que pudieron acceder al conocimiento. De ese modo, asimilaron sus tratados adaptándolos a las exigencias del mundo romano. Sin embargo, no mostraron mucho interés por la ciencia teórica y abstracta, y aunque llegaron a desarrollar sus propios compendios, estos resultaron ser de menor riqueza que los de los griegos y, además, estaban inspirados en ellos. Comenta Grant (2018:26) que los autores enciclopédicos utilizaron los compendios como un repositorio de informaciones de propiedad pública al que se podía saquear, embellecer y readaptar a fin de adecuarlo a sus propósitos. De esta manera, los trabajos científicos y los comentarios de figuras como Platón, Aristóteles, Arquímedes, Teofrasto, entre otros muchos, fueron realmente citados en los compendios como si el recopilador poseyera un conocimiento directo de ellos. No obstante, el recopilador no sólo no estaba realmente

\footnotetext{
${ }^{11}$ En Cuestiones naturales, Seneca se valió de los escritos de Aristóteles, Posidonio y Teofrasto para explicar temas geográficos y fenómenos meteorológicos. Cabe señalar, como bien apunta Edward Grant (2018: 24), miembro de la Academia Internacional de Historia de la Ciencia en París, que aquella obra había trasmitido a la Edad Media una dimensión reducida de la Tierra, lo que había motivado a Colón y a otros de su época a pensar que los mares eran tan estrechos que podían ser fácilmente navegables. Plinio el Viejo había redactado su Historia natural, constituida por 37 libros, pero fue escrita gracias a que el autor había consultado más de dos mil volúmenes escritos por unos cien pensadores antiguos.
} 
familiarizado con los grandes pensadores de la Antigüedad, sino que también se limitaba a repetir lo que algún otro redactor había expresado, en muchos casos de manera distorsionada y hasta extravagante. Esto demuestra de alguna manera que la gran Europa estaba muy alejada de la ciencia griega, y le era imposible elevarse por encima del nivel de las enciclopedias latinas. Es oportuno aclarar ahora que, aunque tengamos por verdadero que la ciencia tiene sus orígenes en Grecia, es otro de los muchos errores y mitos que Europa debe tener presente y cuestionar. En este sentido, Grecia había estado muy influenciada por otros pueblos que presentaban un alto desarrollo científico y cultural. Se estima, por ejemplo, que Egipto era un lugar que estaba mucho más cultivado que Grecia, y que el mismo Pitágoras, durante sus viajes a Oriente, había sido influido notablemente por las matemáticas egipcias, en especial la aritmética y la geometría $^{12}$. A su vez, Pitágoras influyó profundamente en Platón en la cuestión del número. Curiosamente, había viajado al norte de África (Cirene) y más tarde pasó por Egipto, donde pudo haber aprendido la teoría de la reencarnación o metempsícosis, muy propia de la cultura oriental; y, después, como Paul Strathern (2014:18) apunta, fue probable que visitara a algunos magos en Levante, y que pudiera llegar, incluso, por el este, hasta las riberas del Ganges. Realmente, en la India se había dado un gran desarrollo científico en referencia a la naturaleza de la materia, quizás mucho antes de que surgiera en Grecia con el planteamiento que defendió Demócrito acerca del átomo. En este sentido, también los científicos hindúes habían investigado con gran detalle y persistencia toda esa cuestión de que la materia podía estar formada por diminutas partículas, y pudo ser muy posible que los griegos estuvieran muy influenciados por ellos en esa cuestión. Así, el filósofo hindú Kanada (Kashyapa) ${ }^{13}$, que no se sabe a ciencia cierta si vivió en el siglo VI o más bien en el II a.C., identificó cinco tipos de átomos o parmanu, uno por cada uno de los cinco elementos que daban consistencia a la materia: Fuego, agua, tierra, aire, y aether. Precisamente, como apunta Anne Rooney, eran los mismos del modelo de Aristóteles. En cualquier caso, parece que los científicos islámicos reunieron ambas teorías, la hindú y la griega. De este modo: "Había dos formas principales de atomismo islámico, una más cercana al hindú y una con el pensamiento aristotélico. La más extensa fue la obra asharita de

\footnotetext{
${ }^{12}$ Sobre la geometría, expresa Paul Strathern (2014: 23): "Esta palabra significa literalmente "medición de la tierra", y sus técnicas se emplearon en principio para medir los límites de las propiedades, proceso que tenían que repetir cada vez que el Nilo se desbordaba".

${ }^{13}$ Este filósofo hindú nació en Gujarat, India. Su principal área de investigación fue la alquimia, desde la que propuso una teoría atómica de la materia, que según se cree, la ideó mientras caminaba comiendo y arrojando pequeñas partículas de alimento. Se dice que este filósofo cayó en la cuenta de que llegaba un momento en el que no podía seguir dividiendo el alimento en partes cada vez menores, por lo que pensó que debía estar compuesto de átomos indivisibles. Ahora bien, Kanada, a diferencia de los griegos pensaba podían aparecer o desaparecer al instante, y que no se podían destruir por medios físicos o químicos (Rooney, 2013: 23).
} 
Al-Ghazali (1058-1111) (Rooney, 2013: 24). Para este pensador, los átomos son los únicos objetos materiales eternos, los demás objetos no duran mucho tiempo, son "accidentales". Ante esta visión se enfrentó el filósofo islámico Ibn Rushd (1126-1198), Averrores, desde el horizonte interpretativo de Aristóteles. Como expresa Rooney (2013: 24): “Averroes tuvo una enorme influencia en el pensamiento medieval posterior, y tuvo un papel decisivo en que se absorbiera a Aristóteles en la erudición cristiana y judía”.

Ahora bien, a diferencia de la decadencia europea, el mundo árabe de los siglos VIII y IX ya controlaba y traducía gran parte de la ciencia griega (e hindú), a la vez que sus sabios pensadores iban incluyendo sus propias aportaciones a todo ese gran legado milenario. En efecto, en el 820 d.C. se publicó un tratado de álgebra de Mohamet Ibn-Musa de gran trascendencia, que sería traducido después, en el siglo XVI, por Europa. Aristóteles fue estudiado como el gran metafísico y lógico en Bagdad mucho tiempo antes de ser traducido en latín por la España musulmana. Era pues evidente que el mundo musulmán estaba mucho mas adelantado que aquella en cuestiones de astronomía, química, medicina y óptica. En este sentido, y como bien ha expresado el historiador Edward Grant, los europeos occidentales no podían alcanzar el estatus de otros pueblos porque antes de explotar nuevos conocimientos "tenían primero que ser motivados y estimulados en pos de un nuevo interés por la ciencia y la naturaleza" (Grant, 2018: 35), cosa que, en ese momento, no fue posible por su clara inferioridad intelectual.

Durante la alta Edad Media, el quadrivium (aritmética, geometría, astronomía y música) vino a ser el núcleo central del conocimiento científico de Europa. Pero aún así, un profundo oscurantismo científico había calado su columna vertebral durante largo tiempo. Y aunque en el siglo XI tuvo lugar el retroceso de los musulmanes en España y su total derrota en Sicilia, y la Europa cristiana había aprovechado ese vacío de poder para poseer los grandes centros de erudición arábiga y aprovechar así todo su potencial intelectual, lo cierto fue que la vieja Europa no fue más que la sombra de un gigante que todavía caminaba unos cuatrocientos años mucho más adelantado en la Historia.

Después de que la Europa latina medieval se enfrentara durante largo tiempo al mundo árabe-turco sin muchos triunfos, las Cruzadas fueron el primer intento serio para imponerse en el Mediterráneo oriental. Pero el fracaso fue inminente porque, como expresa el mismo Dussel (2001: 347-348), "la Europa latina sigue siendo una cultura periférica, secundaria y aislada por el mundo turco y musulmán, que domina geopolíticamente desde Marruecos hasta Egipto, 
la Mesopotamia, el imperio Mogol del norte de la India, los reinos mercantiles de Malaka, hasta la isla Mindanao en Filipinas en el siglo XIII".

Enrique Dussel (2001: 348, nota 6), siguiendo la hipótesis de Martín Bernal, muestra el movimiento que inauguró Friedrich Schlegel, en 1803, que produjo toda una distorsión de la historia: "de donde la India, el Indoeuropeo, y la decadencia de la centralidad de Egipto (origen de la cultura y la filosofía griega para los griegos desde Herodoto, Platón y Aristóteles hasta el siglo XVIII), permite a la 'ideología' prusiana unificar de manera directa la cultura clásica griega con la alemana: un pensamiento racista, ario, que impulsará a la 'invención' de las historias de la filosofía, donde de Grecia (auto- poiética) y Roma se pasará primero a la Edad Media, y luego directamente a Descartes y Kant".

Todos estos datos históricos nos deben servir para reconstruir con justa precisión la historia que fue eurocentricamente contada para hacer creer al mundo que nosotros, europeos ilustrados y afanosos con las armas y la razón, fuimos el "principio" y, en el algún momento del futuro, seremos el "fin" de la Historia Universal. En realidad, como hemos descrito en este espacio, esa Europa que nos narraron con sumo orgullo y fanatismo, caracterizada por una heroicidad ejemplar, no fue más que un dulce mito, que sus propias víctimas no pueden evitar desvelar, desde su otredad y miseria, como una verdad dolorosa que no puede ser por mucho más tiempo silenciada. Porque la Verdad no está instaurada solamente en el mundo epistémico del conocimiento científico, sino que también se manifiesta, habla de una manera más radical y novedosa, en la corporalidad reveladora del Otro, al que no logramos comprender, ciertamente, muy bien.

\section{3.- Europa: de la "perifera" a la "centralidad" del mundo}

Pero, a veces, la Historia, que está viva y es caprichosa, nos lleva por derroteros desconocidos e inimaginables. Y por un simple azar del destino o de la mala suerte, la Europa "secundaria y aislada", atrasada intelectualmente y casi insignificante en los niveles cultural y político, llegó a convertirse en el "centro" de un territorio mucho más amplio que el de la antigua región euro-afro-asiática. Ciertamente, cuando los españoles llegaron a tierras amerindias, se había iniciado en la historia el nuevo paradigma que nos abriría a lo que hoy conocemos por Modernidad. En cierto modo, todos, privilegiados y excluidos, pobres y ricos, somos hijos legítimos de ésta. Sin embargo, la Modernidad se había impuesto, como advierte Enrique Dussel - desde un Max Weber hasta un Jürgen Habermas - eurocéntricamente, porque se había señalado como punto de partida solamente a fenómenos intraeuropeos, como fueron la 
Ilustración y el Renacimiento. Dussel se enfrenta a esta imposición ilustrada y propone una visión de la Modernidad en un sentido mucho más amplio que abarca otros muchos acontecimientos no provincianos y regionales propios del mundo europeo. Lo cierto es que antes de 1492 nunca había tenido lugar una Historia Mundial, puesto que los imperios no coexistían entre sí. Pero, con el "descubrimiento" de Amerindia, todo el planeta se tornó "el lugar de una sola Historia Mundial". El Atlántico suplantaría para siempre al Mediterráneo. Y Europa, endiosada por un poder que todavía le venía prestado por el azar, se convirtió, por vez primera, en el "centro" de esta Historia, en la que todas las demás culturas se fueron constituyendo lentamente como su "periferia". Por eso, la Modernidad tiene dos caras: una privilegiada, la experiencia de Europa por haberse convertido en amo y señor de todo el territorio que iba encontrando tras su paso implacable; y otra excluida y oprimida, la experiencia de dolor y sometimiento que vivieron los pueblos que fueron invadidos por aquélla. En este sentido, el poder que fue acumulando Europa, tras convertirse en "centro" y manejar a su antojo el "Sistema-Mundo", sólo pudo haber sido posible gracias al haberse impuesto con suma crueldad a Amerindia y destruir su mundo. Con las minas de plata de Potosí y Zacatecas, Europa pudo acumular la riqueza que necesitaba para, finalmente, vencer a los turcos. Sin lugar a dudas, el oro y la plata robada a Amerindia, fruto del trabajo esclavo, sirvieron para que Europa sacara una "ventaja comparativa" con respecto a las culturas turca y musulmana, y se convirtiera en la gran dominadora del "Sistema-Mundo". Como efectos de esta terrible dominación surgieron una serie de fenómenos de gran transcendencia histórico-cultural, como serían la Ilustración, el Renacimiento, el Romanticismo, la Revolución científica, la Revolución industrial y el capitalismo. Todos éstos "acontecimientos" no eran más que instrumentos con los que “domesticar" la subjetividad del Otro, oprimirle, y poder justificar esa terrible dominación de la que estábamos tan orgullosos.

\section{4.- La subjetividad moderna y sus "momentos"}

Nuestra subjetividad moderna se ha ido construyendo, paso a paso, lentamente conforme el europeo iba ganando terreno, conquistando territorios y afianzando su poder aniquilador en el mundo. Es un proceso que todavía está abierto, que sigue en construcción. Podemos diferenciar entonces varios "momentos" esenciales y constitutivos en el desarrollo y consolidación de la subjetividad moderna, dominadora. La primera está comprendida por la Voluntad de Poder, y tiene que ver con la actitud violenta con la que llegamos los europeos a 
las tierras americanas, y con el tipo de poder $^{14}$ que hemos impuesto hasta la actualidad. En la Filosofía de la Liberación podemos encontrar muchas referencias sobre esta actitud dominadora moderna. Tal vez sea la primera manifestación de nuestra subjetividad eurocéntrica. En uno de sus textos, Dussel había expresado:

En nombres de esas leyes, cumpliendo valiosamente esas virtudes, y con el fin de cumplir dicho proyecto (de dominación mundial) salió el hombre europeo "con Colón y sus carabelas del insigne puerto de Palos" en Andalucía, en 1492. Cumpliendo las leyes, Francis Drake, pirata de profesión, asesino de débiles mestizos y violador de mujeres, asoló las costas latinoamericanas y recibió por premio el poder asegurar sus robos en los bancos de Londres y recibir el honor de ser un "Sir" de su británica majestad. ¡He allí la grandeza y la acumulación primera del capitalismo que ahora nos oprime! Su origen fue el oro de los indios y las carnes de los esclavos negros! (Dussel, 1996: 75)

Desde la Voluntad de Poder, la Modernidad emprendió su largo recorrido histórico derramando la sangre del Otro. En el siglo XVI, la situación de los indígenas era muy lamentable debido a la forzosa explotación y la opresión que tenían que soportar, así como también por las numerosas epidemias que causaron grandes estragos entre sus comunidades de vida. Y como la mano de obra indígena era cada vez más escasa, empezamos a importar esclavos africanos. Cada año, unos tres o cuatro mil personas eran arrancadas cruelmente de sus tierras (Angola, Guinea, Senegal o el Congo), y eran llevadas en barcos, en pésimas condiciones, hasta los puertos de Veracruz y Cartagena de Indias, aunque también entraron por Buenos Aires para ser trasladados luego a Brasil. Se trataba de un comercio humano, quizás el primero a ese nivel de sufrimiento y de injusticia, que extendimos los europeos por gran parte del continente americano. En esta primera etapa como Voluntad de Poder, todavía los europeos no teníamos un control y dominación suficiente como para coronarnos los únicos emperadores del mundo e imponer a todas las naciones nuestro proyecto imperialista. Aún estaba la hegemonía de China y del mundo musulmán con las que teníamos que lidiar, y que seguían siendo un gran referente político, económico y cultural.

Un segundo "momento", que alimentaba nuestra subjetividad moderna europea, vino dado por la Desmitificación de la Vida. Con nuestra Voluntad de Poder, que manifestábamos desde una actitud verdaderamente violenta con el Otro, fuimos adquiriendo una nueva forma de percibir toda la realidad. Esta forma de percibir la realidad era muy diferente a la de nuestros

\footnotetext{
${ }^{14}$ En la Política de la Liberación. Arquitectónica, Dussel hace un análisis del poder político que se ha ido desarrollando en la Modernidad, a partir de la Voluntad de Poder del europeo, y escribe: "Desde Hernán Cortés, el primer conquistador - si no contamos la conquista accidentada de Panamá -, que se constituye en 1523 como 'el señor de México-Tenochtitlan', hasta la guerra de Irak, una Voluntad de Poder se ha extendido sobre el planeta Tierra, definiendo el poder político como dominación” (Dussel, 2009: 23).
} 
antepasados o a la de las demás culturas, porque para todas éstas la Naturaleza era una entidad que tenía el don de la Vida, y era sagrada. Pero nosotros empezamos a desmitificar el cosmos y la Naturaleza, los convertirlos en objetos de dominación como hicimos también con los indios de Amerindia. Seguramente, nuestra Voluntad de Poder hizo que interpretáramos la realidad en clave de dominación. Aprendimos a observar los cielos como nuevos espacios a los que conquistar. Y, de algún modo, al haber desacralizado la Naturaleza habíamos transformado nuestra forma de concebir la Vida y de relacionarnos con ella. La mecanizamos instrumentalmente como si fuera una cosa que podíamos controlar sin ningún problema de índole ético, y esto dio lugar a toda una revolución que, tiempo después, un filósofo llamado Alexandre Koyré había llamado Revolución científica. Por eso, la Revolución científica fue mucho más que un cambio de paradigma del conocimiento. Supuso una transformación radical en la forma de percibir la realidad, el hombre y la Vida, que tendría consecuencias terribles en los ámbitos de la política, de la economía, de la cultura, de la religión, de la tecnología, etcétera. En este sentido, destacamos dos pensadores modernos que estaban preparando a Europa para que ésta alcanzara el viejo sueño de convertirse en una hegemonía inmortal, endiosada. Ambos compartieron el mismo proyecto imperial, y creyeron que el conocimiento les daría el poder necesario para transformar la realidad en la que se encontraban inmersos. Para ellos, la Vida había dejado de ser sagrada, era una entidad mecánica que se podía manipular.

Por un lado, Descartes había concebido la materia únicamente como extensión, y, precisamente, por eso mismo, podía explicar el comportamiento del corazón de la misma manera que podía hablar de cualquier cuerpo físico artificial, pues todos ellos están sujetos a las mismas leyes de la mecánica. En el Discurso del método, había dejado escrito: "según las leyes de los mecanismos, que son las mismas que las de la naturaleza, cuando varias cosas tienden a moverse hacia un mismo lado, sin que haya espacio bastante para recibirlas todas [...] las más fuertes deben dar de lado a las más endebles y menos agitadas y, por lo tanto, ser las únicas que lleguen" (Descartes, 2010: 59). Curiosamente, pareciera, que las mismas leyes de la mecánica, que muy sutilmente habían descrito a los cuerpos vivos como máquinas, describieran también la naturaleza mecánica (desvitalizada) de la sociedad moderna en la que vivimos, haciéndonos recordar, al mismo tiempo, aquel "inocente" darwinismo ${ }^{15}$ que terminó, tiempo después, por condenar al sufrimiento a más de las tres cuartas partes de la humanidad, en cuanto

\footnotetext{
${ }^{15}$ Tal vez este texto había sido un factor influyente en el mismo Darwin a la hora de desarrollar su gran obra $E l$ Origen de las especies.
} 
fueron consideradas endebles, y como tales podían desaparecer de la faz de la Tierra sin que supusiera, por ello, algún remordimiento para los fuertes.

Por otro lado, rescatamos la figura de Francis Bacon. Aparentemente, había sido un hombre comprometido con el Estado de su país, un reconocido y prometedor jurista de su tiempo, que jugó un papel clave como lord Chancellor en el reinado de Jacobo I y, sin embargo, había caído en la tentación corrupta del poder ${ }^{16}$. Ahora bien, este comprometido político había dedicado gran parte de su vida a la vanidad de querer transformar el destino de la humanidad, y, de hecho, se había ejercido a fondo en este difícil propósito, para que la historia fuera testigo de un auténtico progreso que hiciera de la mediocridad del hombre un atajo para que éste alcanzara, finalmente, la gloria y el triunfo que tanto se merecía. Para eso, había diseñado con cierta preocupación y paciencia un complejo programa de reforma del saber y del conocimiento. Con esta actitud, fue muy similar a Descartes, sólo que, quizá, su soberbia y ambición por poseer la verdad, y con ella en la mano ser capaz de transformar la realidad humana, habían llegado mucho más lejos. En efecto, si el padre de la Modernidad reconoció ciertos limites imposibles de sobrepasar por la razón humana, puesto que "nuestra voluntad no se determina naturalmente a desear sino las cosas que nuestro entendimiento le representa en cierto modo como posibles" (Descartes, 2010:16), el filósofo inglés no tuvo el menor reparo en creer en el poder infinito de la razón que, unido a la de la experiencia, podría lograr transformar, como hacen las abejas con el néctar de las flores, la naturaleza innata y severa de los objetos:

Las ciencias han sido tratadas o por los empíricos o por los dogmáticos. Los empíricos, semejantes a las hormigas, sólo saben recoger y gastar; los racionalistas, semejantes a las arañas, forman telas que sacan de sí mismos; el procedimiento de la abeja ocupa el término medio entre los dos; la abeja recoge sus materiales en las flores de los jardines y de los campos, pero los transforma y los destila por una virtud que le es propia. Esta es la imagen del verdadero trabajo en la filosofía, que no se fía exclusivamente en las fuerzas de la humana inteligencia y ni siquiera hace de ella su principal apoyo; que no se contenta tampoco con depositar en la memoria, sin cambiarlos, los materiales recogidos en la historia natural y en las artes mecánicas, sino que los lleva hasta la inteligencia modificados y transformados. (Bacon, 2009:81)

Pero, ciertamente, querer transformar la realidad es un propósito exclusivamente venido de nuestro ego moderno, europeo. En este sentido, ¿cómo los antiguos querrían transformar una realidad que es de por sí sagrada? Sería, sin duda, el mayor de los sacrilegios que podría cometer el hombre en relación a la divinidad. Quizás, por ello nunca llegaron a desarrollar una ciencia sustentada en la experimentación, y se quedaron, entonces, suspendidos en él ámbito de la argumentación y de la contemplación del cosmos. Pero los modernos europeos, a partir del siglo

\footnotetext{
${ }^{16}$ En 1621, se había celebrado un juicio en su contra por soborno que le llevó a pagar una condena.
} 
XVII, con una subjetividad basada en un desprecio a la Vida (y al mismo Hombre), no sólo se contentaron con controlar y manipular la historia de los seres humanos desde una política de la dominación, sino que también vieron la posibilidad, desde la ciencia y la técnica, de controlar y transformar la Naturaleza, lo sagrado e intocable para los pueblos originarios y para los antiguos. Precisamente, el lenguaje que utilizaba Francis Bacon en sus obras ya muestra esa subjetividad violenta y dominadora de Europa. Era un pretender transcender y $\operatorname{superar}^{17}$ la subjetividad humana - incluso la misma Vida - y autoprogramar la mente humana como si fuera una máquina perfecta. Era, pues, una lógica completamente dominadora que emergía de un severo autocontrol: "La nueva lógica ha de superar todo subjetivismo. El único remedio saludable es el reconsiderar nuevamente la tarea de la mente, viendo que ésta no recaiga en los vicios inveterados. La obra del conocimiento humano ha de ser metódica, trans-subjetiva, y de eficacia práctica, como si se llevara a cabo por medio de máquinas" (Bacon, 2009: 29). Ese nuevo camino era justamente la experimentación, puesto que "el hombre, servidor e interprete de la naturaleza, ni obra ni comprende más que en proporción de sus descubrimientos experimentales y racionales sobre las leyes de esta naturaleza; fuera de ahí, nada sabe ni nada puede" (Bacon, 2009: 39).

Ciertamente, con el desarrollo de la Revolución científica, Europa pudo producir una nueva tecnología con la que ganarle la batalla a sus enemigos. Porque la guerra, y no el amor a la sabiduría, fue, en realidad, el fundamento de esa Revolución de conocimientos. Los inicios de la Revolución científica estaban centrados en determinadas técnicas para solucionar ciertos problemas relacionados con la navegación oceánica, las artes militares y la minería. En cierta manera, se tenía la certeza de que si se llegaba a solucionar tales problemas, Europa no lo tendría muy complicado a la hora de lograr sus tan ansiados objetivos históricos y culturales. El estudio de la filosofía natural y de la matemática se fueron apoyando en la técnica y mecánica para lograr así un progreso y avance de la eficacia en la estrategia y en el empleo de la artillería, en la guerra. Como bien expresa Paolo Rossi (1970:22), en su obra Los filósofos y las máquinas, la geografía y la astronomía se enseñaban en función de la navegación, y la medicina se fue desarrollando principalmente para medicar y socorrer a los heridos. No era de extrañar, entonces, que William Gilbert fuera un gran conquistador y al mismo tiempo escribiera determinadas obras científicas, como fue De magnete magneticisque corporibus (1600). Y el marinero inglés Robert Norman que, después de haberse pasado media vida surcando mares,

\footnotetext{
${ }^{17}$ Esta cuestión de la superación de la subjetividad humana nos puede recordar, en cierto modo, al proyecto del super hombre que Nietzsche había proyectado desde sus obras.
} 
escribiera acerca del magnetismo y de la declinación de la aguja magnética. Son hombres que han obrado a favor de la gloria imperial de Inglaterra, desde su ego dominador.

Con la Desmitificación de la Vida, los europeos fuimos construyendo la imagen del mundo. Era un mundo mecanizado, estructurado según la razón instrumental europea. Nos encontramos en un momento clave para entender la Historia Mundial, porque Europa ya empezaba a mostrar claros indicios del poder que durante más de dos siglos había acumulado violentamente. Y con la nueva tecnología desarrollada desde una racionalidad mecanicista, se produjo en Inglaterra ${ }^{18}$ la Revolución industrial. La máquina, que en el siglo XVII se había convertido en un modelo para explicar el cosmos y lo vivo, se reencarnó físicamente para llegar a conquistar un nuevo espacio: la fábrica y el obrero. Sin embargo, había primero que desacralizar, desmitificar a la Naturaleza, para después explotarla sin remordimiento bajo la ética burguesa y moderna que antepone, sin cuestionarlo siquiera, la libertad absoluta del mercado y la riqueza desmesurada del capitalista al desarrollo y dignidad de la Vida. En esta tercera etapa en la configuración de la subjetividad moderna tiene lugar la Mistificación del Capital. Se trata de la construcción de la sociedad moderna, consumista y capitalista. A partir de ésta, se llega a sacrificar a pueblos enteros en nombre del capital, que se afirma rotundamente por encima de la Vida. Se ha levantado un nuevo mundo en nombre del capital, y esa Voluntad de Poder y Demitificación de la Vida se han sistematizado en un nuevo comportamiento humano: el individualismo y egoísmo occidental. En el siguiente fragmento de la Política de la Liberación, podemos analizar un ejemplo de estos tres "momentos" constitutivos de la subjetividad moderna:

La cosificación del Otro permite que las aristocracias manejen a los pueblos como pluralidad, multitud, lumpen, animales con lógos pero no hombres, como ya enseñara el clásico Aristóteles acerca de los esclavos en Grecia. El rostro del campesino, expulsado del campo empobrecido, suplicante, es negado como el rostro de alguien y es interpretado como un asalariado más, subsumido realmente, materialmente, como un accesorio conciente maquínico. La máquina, el robot, el "rostro material" del capital ha hecho del "rostro del hombre" un instrumento de sí mismo. (Dussel, 1996:72)

El primero tiene que ver con la Voluntad de Poder de esas aristocracias que pretenden dominar a los pueblos desde un despliegue del poder como dominación. El segundo, la Desmitificación de la Vida, está relacionado con el hecho de que esa Voluntad de Poder conciba al pueblo, al Otro, al Oprimido, como una máquina, "un accesorio conciente maquínico" - como

\footnotetext{
${ }^{18}$ Pensamos que la Revolución industrial no pudo haber surgido antes en China que en Europa por el hecho de que en aquella aún eran más importante los árboles que las máquinas. No había llegado, entonces, a desmitificar la Vida.
} 
dice Dussel -. Esto ocurre cuando esa Voluntad ha desmitificado la Vida del obrero, la ha desacralizado. En tercer lugar, esa Voluntad de Poder que ha desmitificado la Vida ha sustituido el amor a la Vida por una adoración al capital, lo ha mistificado. Mistificación que se ha hecho sistemática desde nuestra sociedad moderna. Estas son, justamente, las tres características propias de nuestra subjetividad, que, dicho sea de paso, están operando simultáneamente en nosotros.

\section{5.-A modo de conclusión. Hacia una subjetividad transmoderna}

La Filosofía de la Liberación nos ha servido para aterrizar en el vasto suelo de la realidad. Nos ha mostrado nuestra identidad aniquiladora desde la exterioridad. Porque es el Otro, la cara oculta de la Modernidad, desde donde debemos pensarnos los europeos. Ese es nuestro sustrato real. Solo tomando conciencia de nuestra auténtica identidad podremos destruir ese mito histórico y transformar nuestra Voluntad de Poder en una Voluntad de Vida con la que poder afirmar la Vida y desmitificar al capital. Tenemos, entonces, que aprender a percibir de otra manera la realidad más allá de la dominación. Debemos sentir (y no sólo pensar) la realidad de otra forma. Y, para eso, es necesario comenzar a mirar con atención el camino que, hasta el momento, hemos transitado.

Dussel había escrito en su biografía cómo él había descubierto a Latinoamérica. Este descubrimiento le ha permitido reflexionar sobre su realidad histórica y cultural. Desde esa misma realidad, la Filosofía de la Liberación ha encontrado las bases teóricas y críticas para pensar una posible y futura liberación latinoamericana (y del resto del mundo). En cualquier caso, el filósofo mexicano había abandonado Argentina en 1957 con el objetivo de realizar un doctorado en España. Pero en ese viaje hacia la Totalidad ya empezaba a despertarse en él un profundo sentir latinoamericano, porque se trataba de una experiencia verdaderamente mística:

Salía del puerto de Buenos Aires en un barco de la compañía "C" (cuatro veces atravesaría el Atlántico por barco). Permanecí en la popa hasta altas horas de la noche. El barco se fue internando en el Río de la Plata. En el atardecer las luces de Buenos Aires se fueron alejando. Sabía que me ausentaba por mucho tiempo. Mi beca era por un año. ¡No sabía, sin embargo, que no regresaría sino diez años después! Como el barco en el que crucé el Atlántico, levanté ancla, y la mantendría en alto hasta que fuera necesario. (Dussel, 1998a: 16)

En ese viaje de la exterioridad a la Totalidad se le fue desvelando la propia identidad de Latinoamérica, su situación de opresión y exclusión. Fue todo un proceso revelador: había tocado a América Latina desde miles de kilómetros, desde el "centro" imperial y poderoso que es Europa: 
Buenos Aires, Montevideo, Santos, Recife...todo un descubrimiento instantáneo y sorprendente de América Latina. El Brasil afroamericano, ¡una novedad absoluta! Después, Dakar en Senegal, el mundo bantú...; después la Casablanca musulmana en Marruecos, el mundo árabe oriental (que con los años habría de conocer y admirar desde Marraquesh a Egipto, la India...y hasta la isla de Mindanao en Filipinas). ¡Todo de pronto y en un viaje de veinticuatro días, con veinte personas en un solo camarote - porque era el pasaje más barato que pude comprar -! Toqué a una América Latina y a un Tercer Mundo que me habían sido absolutamente desconocidos. Yo deseaba con pasión ir a Europa, y yendo hacia ella había ya descubierto, para siempre, el mundo periférico que había estado antes fuera de mi horizonte. (Dussel, 1998a: 16)

De forma similar, Europa debería hacer su viaje hacia la exterioridad del SistemaMundo para re-conocer su esencia histórica y real. Así, tocaría el Renacimiento, la Ilustración, la Revolución científica e industrial y el capitalismo desde Latinoamérica y el Tercer Mundo. Este hecho supondría, sin duda, toda una experiencia reveladora: el encuentro ya no se produciría desde una perversa Voluntad de Poder, sino desde la Voluntad de Vida, desde otra forma de percibir y sentir el mundo y su realidad vivificante. Pero la última instancia es siempre la Vida. Vida como categoría liberadora y principio transformador, porque es a partir de ella desde donde surge ese originario querer vivir de la voluntad, ese amor que se desarrolla y se enriquece profundamente en el mundo del Otro, que es nuestro eterno espejo en el devenir de los tiempos y de los hombres. Finalmente, "cuando acepto a un pobre como Otro y lo respeto en la justicia, dejo de ser un yo absoluto; me limito y no me considero absoluto. Si, por el contrario, no respeto al pobre y lo incluyo en mi totalidad, me considero el centro, me divinizo" (Dussel, 1995: 218). Hace ya algún tiempo que los europeos nos fuimos convirtiendo en ese “centro", y, por ello, nunca llegamos a descubrir al Otro, y, al no hacerlo, tampoco llegamos a tomar conciencia de nosotros mismos, de nuestra esencia dominadora, destructora. Debemos, pues, cultivar una nueva subjetividad que tenga como fundamento el amor a la Vida. Tendríamos que hablar entonces de una subjetividad transmoderna ${ }^{19}$.

\footnotetext{
${ }^{19}$ Dussel habla en sus textos de una Transmodernidad desde la meta-categoría de exterioridad. Dussel va a iluminar aquel análisis que se propone indagar la "positividad" no incluida por la Modernidad, no ya desde los supuestos de la Post-modernidad, sino desde lo que ha ido llamando Transmodernidad: desde la exterioridad negada se levantan vivas aquellas culturas que han nacido con anterioridad a la Modernidad europea, y que aún sobreviven. Esas culturas guardan un potencial de humanidad muy necesario para la construcción de una cultura humana futura, posterior a la Modernidad y al mismo capitalismo. Esa cultura será entonces transmoderna: “Así como las selvas tropicales guardan inmensa cantidad de especies vegetales y animales, que genéticamente son esenciales para el futuro de la Humanidad, de la misma manera las Culturas de la mayoría de la humanidad Excluidas por la Modernidad (que no son ni serán Post-modernas) y por la globalización (porque la miseria es "necesidad de dinero", sin solvencia, y por lo tanto no es mercado) guardan una inmensa capacidad y cantidad de invenciones culturales necesarias para la sobrevivencia futura de la humanidad, para una nueva definición de la relación Humanidad-Naturaleza desde un punto de vista ecológico, desde un punto de vista de relaciones interhumanas de solidaridad (no seductivamente definidas desde el criterio solipsista y esquizoide del mero aumento de la tasa de ganancia)" (Dussel, 2001: 406).
} 


\section{REFERENCIAS}

ADORNO T.W. Y HORKHEIMER. Dialéctica de la Ilustración. Fragmentos filosóficos, Madrid: Trotta, 2018.

BACON, F. Instauratio Magna. Novum organum. Nueva Atlántida, México: Porrúa, 2009.

DESCARTES, R. Discurso del método, México: Editorial Época, 2010.

DUSSEL, E. América Latina: dependencia y liberación. Antología de ensayos antropológicos y teológicos desde la proposición de un pensar latinoamericano, Buenos Aires: Fernando García C., 1973.

— 1492: el encubrimiento del Otro. Hacia el origen del "mito de la Modernidad", La Paz: plural editores, 1994.

Introducción a la Filosofía de la Liberación, Bogotá: Editorial Nueva América, 1995.

—_ Filosofía de la Liberación, Bogotá: Editorial Nueva América, 1996.

"En busca del sentido. (Origen y desarrollo de una filosofía de la liberación)", un proyecto ético y político para América Latina, en Anthropos: huellas del conocimiento, Proyecto A Ediciones, nº 180, 1998a, pp. 13-36.

Ética de la Liberación en la edad de la Globalización y de la Exclusión, Madrid: Trotta: Trotta, 1998b.

Hacia una filosofía política crítica, Bilbao: Descleé de Brouwer, 2001.

Filosofía de la cultura y la liberación, México: Universidad Autónoma de la Ciudad de México, 2006.

Materiales para uns política de la liberación, Mexico: UANL, 2007.

Política de la Liberación. Arquitectónica, Madrid:Trotta, 2009.

FANON, F. Los condenados de la tierra, México: Fondo de Cultura Económica, 2019. *Prefacio de Jean-Paul-Sartre.

GRANT, E. La ciencia física en la Edad Media, México: Fondo de Cultura Económica, 2018.

LAS CASAS, B. Apología, Madrid: Alianza, 1989.

LYOTARD, J.-F. La posmodernidad, Barcelona: Gedisa, 2008.

ROONEY, A. La Historia de la física. De la filosofía natural al enigma de la materia oscura, México: Grupo Editorial Tomo, 2013.

ROSSI, P. Los filósofos y las máquinas 1400-1700, Barcelona: Labor, 1970.

STRATHERN, P. Pitágoras y su teorema en 90 minutos, Barcelona: Siglo XXI, 2014.

VATTIMO, G. El fin de la Modernidad. Nihilismo y hermética en la cultura pos moderna, Barcelona: Gedisa, 2007.

VERNEAUX, R. Textos de los grandes filósofos. Edad Antigua, Barcelona: Herder, 1988. 